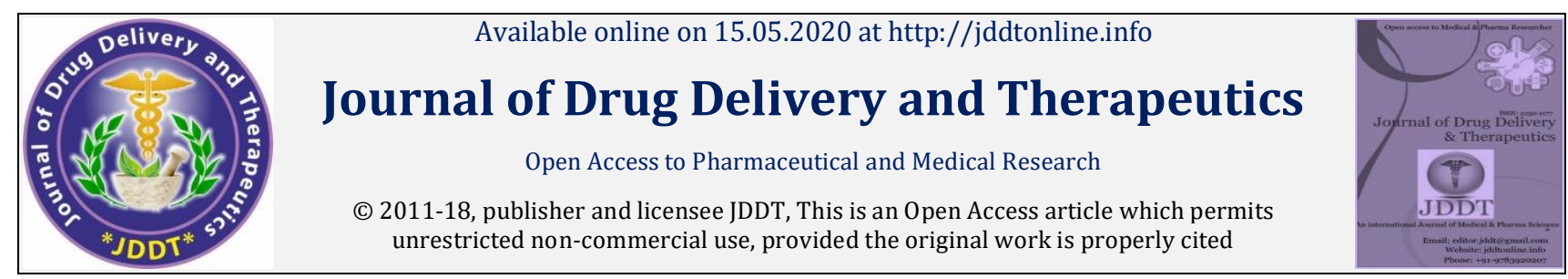

Open Access

Case Study

\title{
The Effect of Meditation in Insomnia due to Stress: A Case Study
}

\author{
Sujeethasai Krishna* \\ Unit of Siddha Medicine, University of Jaffna, Sri Lanka
}

\begin{abstract}
Meditation is the seventh of the eight limbs of Yoga in Patanjali's Yoga Sutras, is also called as Dhyana. Meditation is the process of quieting the mind in order to spend time in thought for relaxation or spiritual purposes. Insomnia is a sleep disorder that regularly affects millions of people worldwide due to stress. Causes of insomnia include psychological factors, medications and hormone levels. Yoga aasanas, Pranayama and meditation are commonly using to manage stress. The aim of this study is to evaluate the effect of meditation in a patient suffering from insomnia due to stress. A case study was carried out in District Ayurveda Hospital - Mullaitivu. A 65 years old female patient came to the Outpatient Department for sleep disturbance. During the interrogation, found that she was in stress. Meditation technique was demonstrated and advised to visit to the clinic alternative days for 2 weeks. The technique was applied for 30 minutes and she felt calm, relax and sleepiness during the procedure. She advised to do regularly in night times. The patient was relived $50 \%$ of stress and could be able sleep well after 2 weeks. According to this study Meditation is good for stress management and can be suggested to the patients who have insomnia due to stress. Further study should be made on large study population, control study and standard meditation protocol for confirmation.
\end{abstract}

Keywords: Yogic Meditation, insomnia, stress

Article Info: Received 04 March 2020; $\quad$ Review Completed 10 April 2020; Accepted 14 April 2020; Available online 15 May 2020

Cite this article as:

Sujeethasai K, The Effect of Meditation in Insomnia due to Stress: A Case Study, Journal of Drug Delivery and Therapeutics. 2020; 10(3):1-3 http://dx.doi.org/10.22270/jddt.v10i3.4065

*Address for Correspondence:

Sujeethasai Krishna, Unit of Siddha Medicine, University of Jaffna, Sri Lanka

\section{Introduction}

Meditation is the seventh of the eight limbs of Yoga in Patanjali's Yoga Sutras, is also called as Dhyana. Meditation is the process of quieting the mind in order to spend time in thought for relaxation or spiritual purposes. Insomnia is a sleep disorder that regularly affects millions of people worldwide due to stress. Causes of insomnia include psychological factors, medications and hormone levels. Attachment to the body is the main cause of physical, psychological and spiritual pain. Meditation facilitates to remove this attachment. Yoga aasanas, Pranayama and meditation are commonly using to manage stress.

\section{Literature review}

Both mind and body are composed of the five elements. The body is mostly composed of the heavy elements of earth, water and fire and also lighter elements of air and ether. But the mind is made up of the lighter elements of air and ether, as it is both pervasive and mobile. Fire affords perception to the mind, water gives it emotion, and earth connects the mind with the body. The mind is formless, pervasive, mobile, ever shifting and changing. Mind and prana always go together. ${ }^{1,6,7}$
Stress is a state of mental or emotional tension resulting from adverse circumstances. Stress causes insomnia. Insomnia is the complaint of inadequate sleep ${ }^{3}$. It takes to difficulty in initiating sleep, maintaining sleep and early morning awakening. Environmental stress, alcohol, medication, physical disorder, psychiatric disorders, restless legs syndrome and periodic movements, sleep wake schedule disorder and learned insomnia are the causes for insomnia.2,3

A meditation session begins with a formal prayer, mantra, Pranayama or visualization. 6,8 There are several types of meditations such as Devotional meditation, Mantra meditation, Kundalini meditation, Deep meditation, Knowledge meditation. 4,5 There are many paths, teachings and traditions of meditation that have their values and relevance to different individuals and cultures.1,4 Meditation helps to deal with pain. It is attuning our will to the divine will and to our higher purpose in life that we follow with our behavior. Meditation implement in healing and balancing purposes. ${ }^{1}$

\section{Objective}

To evaluate the effect of meditation in a patient suffering from insomnia due to stress. 


\section{Methodology}

It was an observational descriptive study carried in District Ayurveda Hospital, Mullaitivu. As a case study the history of illness was taken orally from the patient as well as the examination for neck pain. Meditation technique was demonstrated and advised to visit to the clinic alternative days for 2 weeks. The technique was applied for 30 minutes. She advised to do regularly in night times. The improvement of the condition was taken.

- The patient was seated on yoga mat in meditation room.

- Sitting in silence

- $\quad$ Practicing self inquiry

- Visualization of beautiful scenes in nature to clear the mental field. Hold for a few minutes.

- Collecting memories

- Calling up your soul's inherent freedom from pain

- Repeat a mantra

- $\quad$ Silently observe the mind and lei it empty itself out.

- Think I will completely cure from my pain and stress

- Performing devotional meditation

- Suffer from negative thoughts about themselves

\section{Case report}

○ OPD ticket no -520

○ Age -65 years

- Sex - Female

○ Marital status - Widowed

- Address - Maathalan, Mullaitivu

○ Occupation - Home maker

○ Religion - Hinduism

○ DOE -2017.01.17

A 65 years old female patient came to the Out-patient Department for neck pain for three years and sleep disturbance for the last 7 years. During the interrogation, found that she was planted vegetables in her garden and she is only maintained the plants in the ways of watering, the land. At the beginning she didn't tell but during her $3^{\text {rd }}$ visit she put faith on me and told her family state. She was also in stress and couldn't sleep well for the last 7 years because she lost her husband and son-in-law and she only looked after her physically handicapped daughter and three grand children.

She had been getting treatment of taking allopathic medicine for neck pain and sleep disturbance for the last 3 years.

She had No history of HT, DM, GU

\section{Examination}

1. General examination

Height $-156 \mathrm{~cm}$

Weight - $59 \mathrm{~kg}$

Temperature- $37.2{ }^{\circ} \mathrm{C}$

Pulse-74 bpm
Blood pressure $-130 / 80 \mathrm{mmHg}$

Respiratory rate -15 breaths/min

Heart - Heart sounds heard in all four areas, no added sounds

Lungs - Clear

2. Systemic examination - Neck

Pain - Present

Tenderness- Absent

Heat - Absent

Swelling or any projections - Absent

Redness - Absent

Limited movements - Present

3. Siddha view of diagnosis - Eight tools examination Examination of tongue - Pink

Examination of voice and speech - Normal

Examination of eyes - Normal

Sensation during touch - Normal

Examination of colour and complexion - Dark

Examination of stool - Normal brown

Examination of urine - Straw coloured

Reading of pulse- Vali azhal

4. Body constitution - Vali azhal

5. Season - Munpani

6. Land - Mullai

\section{Line of treatment}

The line of treatment included only palliative treatment.

\section{Treatment and Management}

We gave internal external treatment for neck pain.

The patient was given reassurance. The technique was applied for 30 minutes.

\section{Results and discussion}

\begin{tabular}{|l|l|}
\hline Visits & Sleeping pattern \\
\hline 2017.01 .17 & Awaken frequently in night \\
\hline 2017.01 .21 & Awaken frequently in night \\
\hline 2017.01 .25 & 4 hours awaken in night \\
\hline 2017.01 .27 & 4 hours awaken in night \\
\hline 2017.01 .30 & 4 - 5 hours awaken in night \\
\hline 2017.02 .01 & 5 hours awaken in night \\
\hline 2017.02 .03 & 6 hours \\
\hline 2017.02 .06 & 7 hours \\
\hline 2017.02 .09 & 8 hours \\
\hline
\end{tabular}




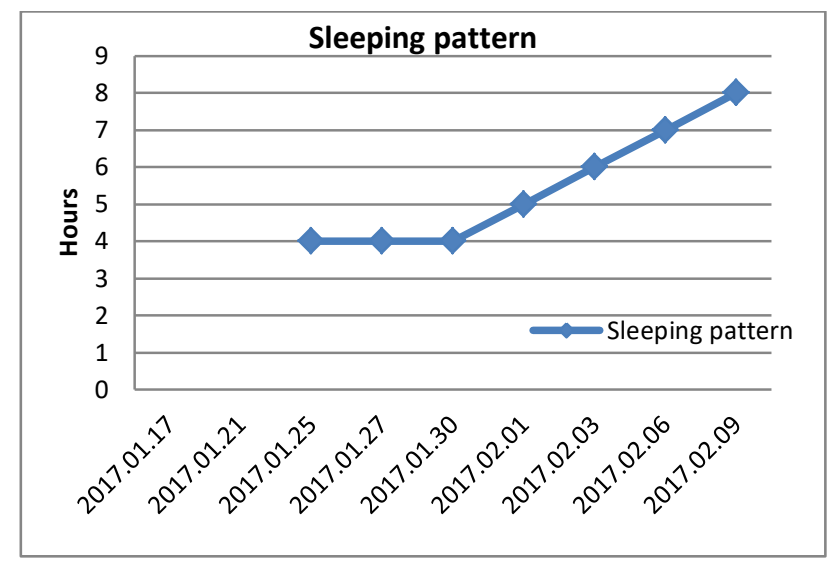

She felt calm, relax and sleepiness during the procedure. The patient stated that she was relived $50 \%$ of stress and able to sleep well after 2 weeks.

\section{Conclusion}

According to this study Meditation is good for stress management and can be suggested to the patients who have insomnia due to stress.

\section{Suggestion}

Further study should be made on large study population, control study and standard meditation protocol for confirmation.

\section{References}

1. David Frawley, Yoga and Ayurveda, Motilal Banarsidass Publishers, New Delhi, $1^{\text {st }}$ Edition, 2013, p283-308

2. John D Stobo et al, The principles and practice of medicine, Lange Medical publishing division, $23^{\text {rd }}$ edition, 1996, p 832 835

3. Kurt J Isselbacher etal, Harrison's principles of internal medicine, Mc.Graw Hill company, 13 ${ }^{\text {th }}$ edition, Volume I, p166169

4. Sundaresa swamy, Yoga Chikitsaium seiyum muraium, Kumaran printers, Chennai $6000017,1^{\text {st }}$ edition, Oct 1999 , p65-80

5. Sundaresa swamy, Ilamaiku rakasiya vazhikal, Kumaran printers, Chennai 6000017, $1^{\text {st }}$ edition, Dec 1999, p110-127

6. S V N Kumarasamy, Arogya Rakasiyam, Kumaran printers, Chennai 6000021, $2^{\text {nd }}$ edition, 1954, p697-702

7. Ira Andiyappan, Arogya Vazhvu, Bharathi printers, Chennai $6000017,4^{\text {th }}$ edition, Oct 2001, p33-35

8. Ira Andiyappan, Enrum Izhmai, Bharathi printers, Chennai 6000017, $1^{\text {st }}$ edition, Dec200, p31-33 